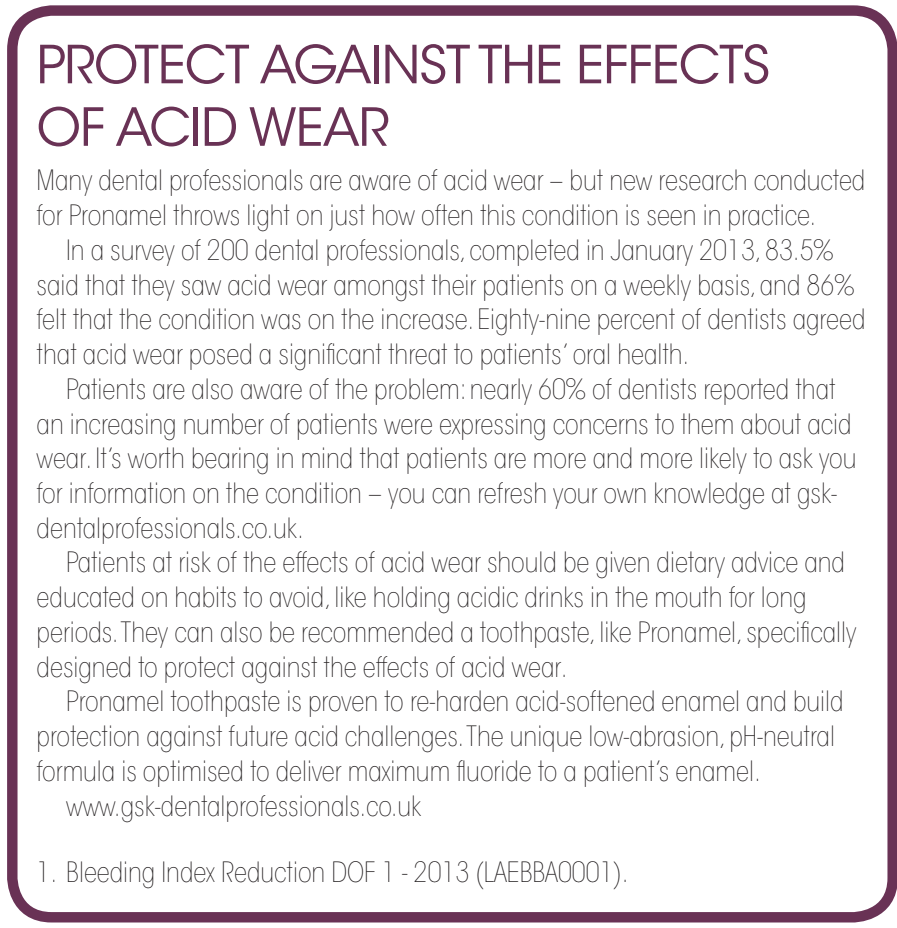

\section{STUDENTS DESIGN STRIKING NEW PRODUCT}

Two dental students from Queen's University Belfast have designed a brand new oral health product: Flipper Hygienic Toothbrush Holders, distributed exclusively by CW Distributions.

Flipper anti-bacterial toothbrush holders offer a cleaner, more hygienic and fun way to store toothbrushes. The children's ranges are intended to motivate children into looking after their oral health. The 'Animo Jr' range features 12 animal designs including a giraffe, tiger, pig, panda and cow; in 'ToothFairy' there are 12 attractive and colourful tooth-shaped designs, each with a name such as 'Kisses', 'Lime' and 'Yeah!'

There is also an adult version of the product, 'Basic', with a sleek and simple design

Fourth year students William Maguire and Callum McCandless developed the Hygienic Toothbrush Holders after spending time on work placements in the community at schools and youth centres. They even plan to branch out into a teenage range and to produce an anti-bacterial razor holder.

The young entrepreneurs hope to give something back to their community through raising awareness of good oral health and at the same time the products should help them pay off their student loans.

Many dental practices already stock the Hygienic Toothbrush Holders, as well as MediCare - the largest chemist retail chain in Northern Ireland - and a number of smaller chains.

To find out more visit wnw. mytlipperuk.com

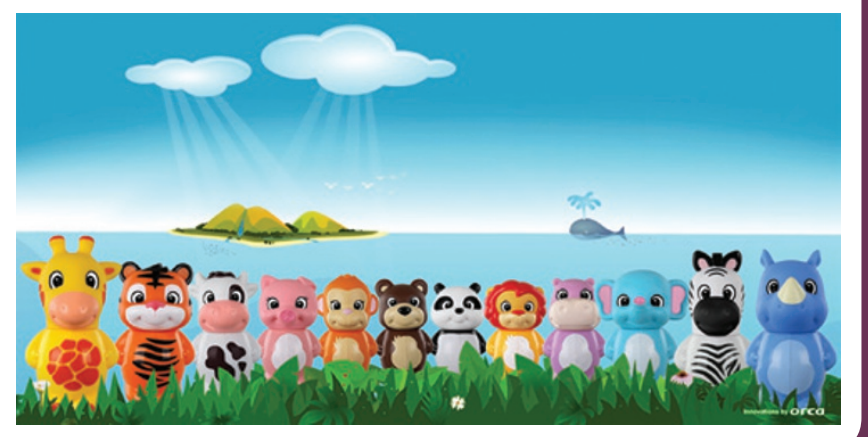

TREATING GUM DISEASE WITHOUT CHLORHEXIDINE

New Listerine Advanced Defence

Gum Treatment from Johnson \& Johnson

cuts gingival bleeding by

over $50 \%$ in just four weeks when

used after brushing.

Advanced Defence Gum Treatment is the newest mouthwash in a range that addresses specific oral care conditions. Used as an adjunct to mechanical cleaning, Advanced Defence Gum Treatment helps to treat gum disease as it is formulated with LAE (Ethyl Lauroyl Arginate) technology, which forms a physical coating on the pellicle to prevent bacteria from accessing and attaching to the pellicle proteins, interrupting plaque biofilm formation and maturation

Advanced Defence Gum Treatment has been shown to significantly reduce gum
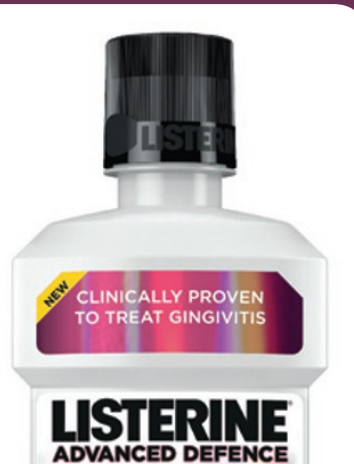
ADVANCED DEFENCE GUM TREATMENT

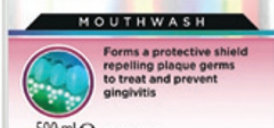

$500 \mathrm{mle} \cos \mathrm{pent}$

DESIGNED TO NOT
CAUSE STAINING

disease at two weeks and cut gingival

bleeding by $50.9 \%$ in just four weeks.' In

addition, Advanced Defence Gum Treatment is designed not to

cause staining and has a crisp mint taste.

The Advanced Defence range also includes Advanced Defence Sensitive

and Advanced Defence Cavity Guard.

For more information visit www. listerine.co. uk/products/advanced-defence-gum

RESULTS BASED TRAINING IS A MUST

A well-known, well respected

and seasoned team trainer and

practice development specialist

Tracy Stuart has moved on to

pastures new and is Founder and

Director of her new company, NBS

Training. Tracy's new company

will deliver:

- Focused and customised

training for ALL of the dental

team - dentists, hygienists,

managers, nurses and

reception team - nobody

is exempt

- Affecting changes to the

business that are positive and

measurable in both private

and NHS practices

- A no nonsense approach!

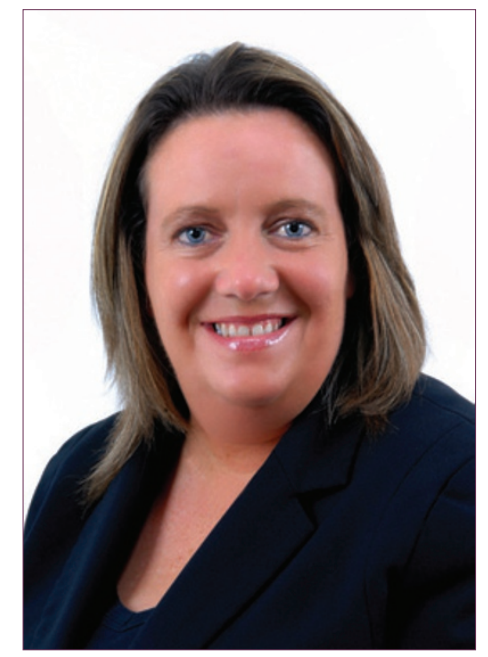

Tracy commented, 'I have always believed that a results-based approach works best with any of the training and practice development programmes I have provided. This remains the ethos of NBS Training - we are candid in our approach but how else can we expect you to understand and embrace the changes needed to bring you the results you are after? Teams respect that I am not afraid to roll up my sleeves and get involved - not just talk a good game:

Tracy has been successfully delivering training programmes for many years and has over 20 years' experience in developing and managing dental practices. For more information on NBS Training and the programmes offered visit uww.nbstraining.co.uk or call 01438217944

If you would like to promote your products or services direct to the dental industry in the brand new publication BDJ TEAM, launching March 2014, telephone Steve Brown on 02078434724. 